\title{
Color Stability of Flowable Composites in Different Viscosities
}

\author{
Bora Korkut (D), Cigdem Haciali (15) \\ Marmara University, Faculty of Dentistry, Department of Restorative Dentistry, Istanbul, Turkey.
}

Correspondence Author: Bora Korkut

E-mail: bora.korkut@marmara.edu.tr

Received: $25.10 .2020 \quad$ Accepted: 04.12.2020

\begin{abstract}
Objective: This in vitro study was aimed to evaluate the color stability of resin-based composite materials in different viscosities immersed in various colorant solutions.

Methods: 250 composite samples of A2 shades were prepared using two high-viscosity flowable composites (G-aenial Injectable, GC, Tokyo, Japan; Estelite Super Low Flow, Tokuyama Dental, Japan A2 shade), a bulk-fill flowable composite (Filtek Bulk-Fill, 3M, USA), a lowviscosity flowable composite (Filtek Ultimate Flowable, 3M, USA), and a packable composite (Filtek Ultimate, 3M, USA). Samples were polymerized and polished from both sides with a LED curing unit (Valo Grand, Ultradent, Switzerland) and polishing discs (SofLex, 3M, USA). Then divided by test groups ( $n=10$ for each) regarding colorant solutions; coke (CocaCola Company, USA), tea (Yellow Label, Lipton, Rize, Turkey), coffee (Nescafe Classic; Nestle, Switzerland), red wine (Doluca, Öküzgözü, Doluca, İstanbul, Turkey), and physiologic saline as the control solution. Samples were discolored for 144 hours with solutions in an incubator at $37^{\circ} \mathrm{C}$, and repolished after discoloration. Color measurements were performed using a clinical spectrophotometer (EasyShade IV, Vita, Germany) and a colorimeter (ShadeStar, Dentsply Sirona, USA). Two-way Anova test and Tukey HSD test were used for statistical analyses.

Results: Composite material and colorant solution were considered effective factors for influencing the color change, regarding after discoloration scores ( $p<0.001, p<0.001$, respectively). In addition, colorant solution was found more effective than the type of composite. Filtek Ultimate Flowable presented significantly the highest level of color change among others ( $p<0.001)$, for both 'after discoloration $(5,34 \pm 3,78 b$ )' and 'after repolishing $(3,93 \pm 2,23 \mathrm{~b})$ ' periods. No significant difference in color change was found between Gaenial Injectable, Estelite Super Low Flow, Filtek Bulk Fill Flowable, and Filtek Ultimate, and all showed imperceptible color changes $\left(\Delta \mathrm{E}^{*}<3.7\right)$. Red wine solution showed significantly the highest level of color change $(8,00 \pm 2,08 d)$ among other colorant solutions $(p<0.001)$, and followed by coffee $(4,59 \pm 1,52 c)$, tea $(3,38 \pm 1,21 b)$, and coke $(1,58 \pm 0,99 a)$, respectively. A strong relation was found between the spectrophotometer and colorimeter measurements.

Conclusion: Viscosity was considered an effective factor for discoloration of RBCs. Color stability of high viscosity flowable composite materials were found to be good and similar to packable composite. Samples immersed in red wine showed the greatest level of discoloration and followed by coffee, tea, and coke. The repolishing procedure was considered effective for reversing back the surface discoloration of composite materials.
\end{abstract}

Keywords: Discoloration, repolishing, flowable composite, viscosity, color stability

\section{INTRODUCTION}

Resin-based composites (RBCs) are frequently preferred in dental clinical practice with regards to multiple advantages such as improved optical and mechanical properties, color stability, ease of repair, and single visit treatment option (1). However, there are many studies indicating these materials are susceptible for color change in long-term use $(2,3)$. Color stability of resin composite materials may vary depending on the surface roughness, which is directly related to the finishing and polishing procedures $(4,5)$. Restorations with smoother surfaces result in fewer leakage, less microbial dental plaque build-up, less gingival irritation in the gums, fewer caries, and therefore less discoloration (6). Minimum surface roughness was reported when using transparent mylar strips without finishing and polishing protocols (7), however, composite restorations may not generally be finished in this way in clinical conditions and need finishing and polishing to remove the outer weak polymerized and softer surface. An accurate and effective finishing and polishing protocol with proper materials are essential for maintaining the color stability of a RBC restoration (8).

Recently, many manufacturers have presented RBC materials with various filler content and viscosity for clinical use. There is a proven relationship between the inorganic filler 
type, shape, and proportion as well as the surface hardness, abrasion resistance, and polishability with viscosity, regarding the resin-based composites (5). Previously, it has been reported that the restorations performed with the resins with low polishability, featured low surface gloss clinically in longterm, and the polishability varied among the resin type (5). In terms of polishability, generally microhybrid resin composites (filler particle size ranging from 0.04 to $2 \mu \mathrm{m}$ ) were considered as more disadvantageous compared to the nano-hybrid and nano-filled resin composites filler (filler particle size ranging from 0.005 to $0.01 \mu \mathrm{m})(9,10)$. However, some researchers determined that the micro-hybrid and nano-hybrid composite materials do not differ significantly in terms of surface hardness and polishability, as well as the color stability (11).

It is a fact that RBCs change color in time due to internal and external factors (8). Internal discolorations may include only dentin tissue, enamel tissue, or both tissues at the same time, whereas, external discolorations include only the enamel. Internal discoloration is related to the structure of tooth and is formed in deeper layers as a result of the physicochemical reactions occurring in the restoration by the contact to a coloring agent $(6,12)$. External discolorations may occur depending on some factors such as deterioration of restoration surfaces, improper finishing and polishing processes, the effect of coloring agents in beverages, smoking, poor oral hygiene, or dietary habits $(12,13)$. Accordingly, the manufacturers have developed advanced finishing and polishing materials to maintain the discoloration potential of the RBCs. Recently, there are various finishing and polishing systems in the market for polishing RBC restorations. Metal, rubber, or silicon-based polishing materials can be found in different size, shape and structure with various abrasive particles. Contemporary polishing materials are in disc or spiral wheel shape and include diamond and/or aluminum oxide surface coating $(8,14)$.

This in vitro study is aimed to assess the color stability of five RBC materials in different viscosity (a packable, a bulk-fill flowable, two high-viscosity flowable, and a low-viscosity flowable) after discoloration in five different colorant solutions.

The $h_{1}$ hypotheses of the study are considered as follows:

(1) the viscosity, which is influenced by the particle size and content of the material, is an influencing factor for discoloration of RBCs, (2) The discoloration of the resin composites was affected by the type of colorant solution.

\section{MATERIALS AND METHODS}

\subsection{Preparation and Distribution of the Samples}

In this study, five different resin-based composites in different viscosities were used: Gaenial Injectable Flow, A2 shade (GC, Tokyo, Japan); Filtek Ultimate, A2 Body shade (3M, USA); Filtek Bulk-Fill Flowable, A2 shade (3M, USA); Estelite Universal Flow Super Low, A2 shade (Tokuyama Dental, Japan); Filtek Ultimate Flowable, A2 shade (3M, USA) (Table 1).

Table 1. Type, content and manufacturer of resin composites used in the study

\begin{tabular}{|c|c|c|c|c|}
\hline Material & Code & Type & Content & Manufacturer \\
\hline $\begin{array}{l}\text { G-aenial } \\
\text { Injectable } \\
\text { Flow }\end{array}$ & GIF & $\begin{array}{l}\text { Nano- } \\
\text { hybrid }\end{array}$ & $\begin{array}{l}\text { The resin matrix: UDMA, Bis-MEPP, TEGDMA, } \\
\text { pigment, photoinitiator } \\
\text { The filler: } 69 \mathrm{wt} \%, 50 \text { vol \%; Silicon dioxide, strontium } \\
\text { glass }(10-200 \mathrm{~nm}) .\end{array}$ & $\begin{array}{l}\text { GC Corp., } \\
\text { Tokyo, Japan }\end{array}$ \\
\hline $\begin{array}{l}\text { Filtek } \\
\text { Ultimate }\end{array}$ & $\mathrm{FU}$ & $\begin{array}{l}\text { Nano- } \\
\text { filled }\end{array}$ & $\begin{array}{l}\text { The resin matrix: Bis-GMA, UDMA, TEGDMA, Bis- } \\
\text { EMA } \\
\text { The filler: } 78.5 \mathrm{wt} \%, 63.3 \mathrm{vol} \% \text { Silica / zirconium (0.6- } \\
10 \mu \mathrm{m}) \text {, zirconium particles }(4-11 \mathrm{~nm}) \text {. }\end{array}$ & $\begin{array}{l}\text { 3M, St. Paul, } \\
\text { MN, USA }\end{array}$ \\
\hline $\begin{array}{l}\text { Filtek } \\
\text { Bulk-Fill } \\
\text { Flowable }\end{array}$ & FBF & $\begin{array}{l}\text { Nano- } \\
\text { filled }\end{array}$ & $\begin{array}{l}\text { The resin matrix: UDMA, Bis-GMA, Bis-EMA, } \\
\text { Proacrylate resins, TEGDMA } \\
\text { The filler: } 64.5 \mathrm{wt} \%, 42.5 \mathrm{vol} \% \text { YBF3 fillers }(0.1-5.0 \\
\mu \mathrm{m}) \text {, zirconium silica particles }(0.01-3.5 \mu \mathrm{m}) \text {. }\end{array}$ & $\begin{array}{l}\text { 3M, St. Paul, } \\
\text { MN, USA }\end{array}$ \\
\hline $\begin{array}{l}\text { Estelite } \\
\text { Universal } \\
\text { Super } \\
\text { Low Flow }\end{array}$ & ESLF & $\begin{array}{l}\text { Nano- } \\
\text { hybrid }\end{array}$ & $\begin{array}{l}\text { The resin matrix: Bis-GMA, Bis-MPEPP, TEGDMA, } \\
\text { UDMA } \\
\text { The filler: } 70 \% \text { wt, } 56 \% \text { vol Supra-nano spherical filler } \\
\text { (200nm silicon and zirconium). }\end{array}$ & $\begin{array}{l}\text { Tokuyama } \\
\text { Dental Co., } \\
\text { Tokyo, Japan }\end{array}$ \\
\hline $\begin{array}{l}\text { Filtek } \\
\text { Ultimate } \\
\text { Flowable }\end{array}$ & FUF & $\begin{array}{l}\text { Nano- } \\
\text { filled }\end{array}$ & $\begin{array}{l}\text { The resin matrix BIS-GMA, TEGDMA, EDMA, } \\
\text { benzotriazole, diphenyl iodonium hexafluorophosphate, } \\
\text { dimethacrylate, ytterbium flüoride } \\
\text { The filler: } 65 \mathrm{wt} \%, 46 \mathrm{vol} \% \text { Silica }(75 \mathrm{~nm}) \text {, zirconium } \\
(5-10 \mathrm{~nm}) \text {, silane treated ceramic and silica. }\end{array}$ & $\begin{array}{l}\text { 3M, St. Paul, } \\
\text { MN, USA }\end{array}$ \\
\hline $\begin{array}{l}\text { TEGDMA: } \\
\text { EDMA: eth }\end{array}$ & ene gly & odımethe & $\begin{array}{l}\text { imethacrylate, Bis-EMA: bisphenol A glycol methacrylate ett } \\
\text { thacrylate, UDMA: urethane dimethacrylate, HEMA: hydroxy } \\
\text { ate, Bis-MPEPP: 2,2-bis[(4-methacryloxy polyethoxy)phenyl }\end{array}$ & $\begin{array}{l}\text { ated, } \\
\text { metacrylate, } \\
\text { ane }\end{array}$ \\
\hline
\end{tabular}


On top of a glass, the selected resin composite was placed in a rubber mold in $2 \mathrm{~mm}$ thickness and $8 \mathrm{~mm}$ in width and covered with a transparent mylar strip and another glass at the top. Excessive composites were removed slightly and light finger pressure was applied on top of the glass while polymerizing. The polymerization was performed from both sides of the samples, using a LED curing unit (Valo Grand, Ultradent, Switzerland) for $20 \mathrm{~s}$ per surface, at irradiation of $1000 \mathrm{~mW} / \mathrm{cm}_{2}$. All samples were stored in distilled water for a day. Then both surfaces of the samples were roughened to ensure surface standardization before initial color measurements. Coarse grain $(50-90 \mu \mathrm{m})$ aluminum oxide coated polishing discs (SofLex Discs, 3M, USA) were used without water cooling at $5000 \mathrm{rpm}$ for the surface standardization. A new disk was used for each sample for $20 \mathrm{~s}$ per side by a single operator. The roughened surfaces were cleaned from debris continuous water and kept in distilled water at room temperature for 1 day before polishing.

A total of 250 composite samples of five different composite group ( $n=50$ for each group) were prepared. Each group was divided into five sub-groups of four different colorant solutions and a control group ( $n=10$ for each sub-group).

\subsection{Polishing Protocol}

Previously accepted gold standard surface polishing material for RBCs, SofLex discs were used for the polishing of the samples (15). All standardized pre-roughened samples were polished from both sides using medium grain $(10-40 \mu \mathrm{m})$, fine grain $(3-9 \mu \mathrm{m})$, and superfine grain $(1-7 \mu \mathrm{m})$ aluminum oxide discs, respectively. The discs were used by a single operator without water cooling at $5000 \mathrm{rpm}$ for $20 \mathrm{~s}$ per side. The discs were renewed for each sample.

All samples were repolished again after the discoloration was completed and the records were obtained. Medium grain $(10-40 \mu \mathrm{m})$, fine grain $(3-9 \mu \mathrm{m})$, and superfine grain (1-7 $\mu \mathrm{m})$ aluminum oxide discs were used respectively for repolishing protocol.

\subsection{Discoloration Protocol}

Following obtaining the initial color records, the samples were divided into five sub-groups for the immersion in the coloration solutions. The solutions were: coke (CocaCola Company, USA), tea (Yellow Label, Lipton, Rize, Turkey), coffee (Nescafe Classic; Nestle, Switzerland), red wine (Doluca, Öküzgözü, Doluca, Istanbul, Turkey), and physiological solution (Table 2).

An incubator (Cultura Incubator, Ivoclar Vivadent, Lichtenstein) was used to set the temperature at a constant $37^{\circ} \mathrm{C}$ for all solutions, to simulate human body temperature (16). The samples in coke group $(n=10)$ were immersed in $50 \mathrm{ml}$ CocaCola for $144 \mathrm{~h}$ with daily solution renewal (17). The samples in tea group $(n=10)$ were immersed in tea for $144 \mathrm{~h}$ with daily solution renewal (16). The tea solution was prepared by immersion of a teabag in $50 \mathrm{ml}$ of boiling water for $5 \mathrm{~m}$. The samples in coffee group $(n=10)$ were immersed in coffee for $144 \mathrm{~h}$ with daily solution renewal. The coffee solution was prepared by dissolving $3 \mathrm{~g}$ of coffee in $50 \mathrm{ml}$ of boiling water $(16,17)$. The samples in wine group $(n=10)$ were immersed in $50 \mathrm{ml}$ of red wine for $144 \mathrm{~h}(16,17)$. The samples in the control group were kept in $50 \mathrm{ml}$ physiological solution for $144 \mathrm{~h}$. All the samples were cleaned from debris and all solutions were renewed daily (17). It was reported that $144 \mathrm{~h}$ of immersion in vitro corresponded to about 6 months of immersion in colorant drinks in vivo, previously $(16,17)$.

Table 2. Type, content, manufacturer, and $\mathrm{pH}$ of staining solutions used in the study

\begin{tabular}{llll}
\hline Solution & Brand & Manufacturer & pH \\
\hline Coke & CocaCola & $\begin{array}{l}\text { The CocaCola Company, FL, } 2.52 \\
\text { USA }\end{array}$ & 6.50 \\
Tea & Yellow Label & Lipton, Rize, Turkey & 6.50 \\
Coffee & Nescafe Classic & Nestle, Vevey, Switzerland & 4.50 \\
Red Wine & $\begin{array}{l}\text { Doluca } \\
\text { Öküzgözü }\end{array}$ & Doluca, Istanbul, Turkey & 3.50 \\
$\begin{array}{l}\text { Control } \\
\text { Solution }\end{array}$ & $\begin{array}{l}\text { Physiologic } \\
\text { Saline }\end{array}$ & - & 5.50 \\
\hline
\end{tabular}

\subsection{Evaluation and Statistical Analysis}

Color measurements were performed in three different periods [i.e., before discoloration $\left(T_{1}\right)$, after discoloration $\left(T_{2}\right)$, and after repolishing $\left(T_{3}\right)$ ] for each sample. $T_{1}$ assessment was considered the initial record of the samples after polishing procedures. Before each measurement, the samples were slightly cleaned from debris with continuous water and dried. The color measurements were performed using a clinical contact type spectrophotometer device (EasyShade 4, Vita, Germany) and a clinical contact type colorimeter device (ShadeStar, Dentsply Sirona; USA) by a single experienced researcher on a gray background $\left(C I E L^{*}=94.48, a^{*}=-0.16\right.$, and $b^{*}=-0.21$ ). Before the measurements, both devices were calibrated with individual calibration stands. The tip of the devices was located in contact, perpendicular to the middle of the sample surfaces.

Surface color of the samples was assessed regarding the $E^{*}$ and Vita* values, both generated from CIE $L^{*} c^{*} h^{*}$ color coordinates. $E^{*}$ values and Vita* values for each sample were obtained for $T_{1}, T_{2}$, and $T_{3}$ periods. Previously, various $\Delta E^{*}$ cutpoint values were reported for evaluating the level of color change such as; $\geq 2$ (18), $\geq 2.6(19), \geq 3.3(20), \geq 3.7(21,22)$ for perceptibility, and $\Delta E^{*}<2(18),<5.5(19)$, and $<6.8$ (22) for acceptability. In this study, respective cutpoints for $\Delta \mathrm{E}^{*}$ scores were considered $\geq 3.7$ and $<5.5$ for perceptibility and acceptability levels of color change. Level of color changes $\left(\Delta \mathrm{E}^{*}\right.$ scores) was assessed by calculating the differences between $T_{2}$ $-\mathrm{T}_{1}\left(\Delta \mathrm{E}_{1}\right), \mathrm{T}_{3}-\mathrm{T}_{2}\left(\Delta \mathrm{E}_{2}\right)$, and $\mathrm{T}_{3}-\mathrm{T}_{1}\left(\Delta \mathrm{E}_{3}\right) . \Delta \mathrm{E}_{1}$ represents the level of discoloration after immersion in staining solution, $\Delta \mathrm{E}_{2}$ represents the level of brightening after repolishing, and $\Delta \mathrm{E}_{3}$ represents the level of color matching/ mismatching of repolished samples with the initial scores. 
Besides, recorded Vita* color codes from B1 to D4 were converted to numerical values of $1-16$, in accordance with Vita Classic Shade Guide Scale. $\Delta$ Vita* scores were assessed to evaluate the correlation between the two color measurement techniques. $\Delta V$ ita* scores were assessed by calculating the differences between $T_{2}-T_{1}\left(\Delta V\right.$ Vita $\left._{1}\right) T_{3}-T_{2}$ $\left(\Delta\right.$ Vita $\left._{2}\right)$, and $\mathrm{T}_{3}-\mathrm{T}_{1}\left(\Delta \mathrm{Vita}_{3}\right)$.

The data were analyzed using IBM SPSS V23 software. The $\Delta \mathrm{E}^{*}$ values in each measurement period according to the composites and the colorants were analyzed using Two-way Anova test. The significant differences were investigated using Tukey HSD test of multiple comparisons. The correlation between the Vita* and $\Delta \mathrm{E}^{*}$ scores were investigated with Kappa test statistics. The \pm standard deviations were presented and ' $p$ ' value of .05 was deemed significant.

\section{RESULTS}

Composite material and colorant solution were considered effective factors for influencing the color change, regarding $\Delta \mathrm{E}_{1}$ $(p<0.001, p<0.001), \Delta E_{2}(p<0.001, p<0.001)$, and $\Delta E_{3}(p=0.009$, $p<0.001)$ scores, respectively. Additionally, the type of discoloration solution was found more effective than composite material type for all evaluation periods (Table 3 ).

Table 3. Univariate test statistics of composite and solution factors.

\begin{tabular}{|c|c|c|c|c|c|c|}
\hline & \multicolumn{2}{|c|}{$\Delta \mathrm{E}_{1}$} & \multicolumn{2}{|c|}{$\Delta \mathrm{E}_{2}$} & \multicolumn{2}{|l|}{$\Delta \mathrm{E}_{3}$} \\
\hline Factor & $\mathrm{F}$ & $p$ & $\mathrm{~F}$ & $p$ & $\mathrm{~F}$ & $p$ \\
\hline Composite & 27.308 & $<0.001$ & 12.724 & $<0.001$ & 3.596 & 0.009 \\
\hline Colorant & & & & & & \\
\hline Solution & 252.212 & $<0.001$ & 80.098 & $<0.001$ & 52.684 & $<0.001$ \\
\hline Composite* & & & & & & \\
\hline $\begin{array}{l}\text { Colorant } \\
\text { Solution }\end{array}$ & 4.983 & $<0.001$ & 2.656 & 0.002 & 2.793 & 0.001 \\
\hline
\end{tabular}

F: Univariate test statistics

According to $\Delta \mathrm{E}_{1}$ scores, FUF composite presented significantly the greatest level of color change $(5,34 \pm 3,78$ b) among other composite materials, regardless of the solution type $(p<0.001)$, which was perceptible $(\geq 3.7)$ but acceptable $(<5.5)$. In addition, there was no significant difference in color change between the scores of GIF $(3,40$ $\left.\pm 2,52_{\mathrm{a}}\right), \operatorname{ESLF}\left(3,21 \pm 1,99_{\mathrm{a}}\right), \operatorname{FBF}(3,18 \pm 2,65 \mathrm{a})$, and FU $(3,37$ $\pm 2,61_{\text {a }}$ ) composites and all were not perceptible $(\leq 3.7$; Table 4). Regardless of the composite type, samples in red wine solution showed significantly the highest level of color change ( $p<0.001 ; 8,00 \pm 2,08 d$ ) among other solutions, which was not acceptable $(>5.5)$. The level of color change for coffee group $(4,59 \pm 1,52 c)$ was also significantly different and perceptible, but acceptable. Although tea group presented significantly a greater level of color change $(3,38 \pm 1,21$ b) compared to water and coke groups $(p<0.001)$, these three solutions showed imperceptible color changes. In terms of composite* solution interactions, combinations of red wine with all composites presented not acceptable color changes $(\geq 5.5)$. Moreover, coffee combination with FUF presented not acceptable color change. Red wine combination with FUF $\left(11,32 \pm 1,38_{A}\right)$ presented significantly the greatest level of color change $(p<0.001)$. All combinations with water and coke presented an imperceptible level of color changes. The interactions of tea with all the composites also showed an imperceptable level of color changes, except with FUF $(4,94$ $\left.\pm 0,39_{C D E}\right)$ which was perceptible but acceptable (Table 4).

According to $\Delta \mathrm{E}_{2}$ scores, all composites presented imperceptible $\Delta \mathrm{E}^{*}$ levels regardless of the solution type, except FUF $(3,93 \pm 2,23 \mathrm{~b})$, which was also significantly different $(p<0.001)$. Regardless of the composite type, samples in both red wine $(4,36 \pm 1,29 c)$ and coffee $(4,38 \pm$ 1,36 ) solutions showed significantly higher and perceptible $\Delta E^{*}$ levels ( $p<0.001$; Table 4). $\Delta E^{*}$ levels for water, coke, and tea groups was all imperceptible. In terms of composite*solution interactions, all red wine combinations except with ESLF and combinations of FUF with tea and coffee presented statistically similar, perceptible $\Delta E^{*}$ levels $(p>0.05)$, which were also significantly higher than the other combinations $(p<0.001)$.

According to $\Delta \mathrm{E}_{3}$ scores, all composite materials presented imperceptible $\Delta E^{*}$ levels $(\leq 3.7)$, regardless of the solution type. Also, the samples in all solutions presented imperceptible $\Delta \mathrm{E}^{*}$ levels, regardless of the composite type, except red wine group $(3,77 \pm 1,90$ c), which was perceptible. In terms of composite*solution interactions, the combination of FUF composite with red wine showed significantly the highest $\Delta E^{*}$ level among all $(p<0.001)$, which was the only perceptible value $\left(6,26 \pm 1,7_{A}\right.$; Table 4).

Distribution of the scores of 0 - other scores for $\Delta V i t a *$ and $<3.7-\geq 3.7$ scores for $\Delta \mathrm{E}^{*}$ were analyzed, regarding the perceptible and imperceptible scores for both methods.

A very good correlation was found between the $\Delta \mathrm{E}^{*}$ and $\Delta$ Vita* scores for all the evaluation periods $(p<0.001$ for each period; Table 5).

Table 5. Correlation between $\Delta E^{*}$ and $\Delta V i t{ }^{*}$ scores.

\begin{tabular}{ccc}
\hline Evaluation Period & Kappa & $p$ \\
\hline $\mathrm{T}_{2}-\mathrm{T}_{1}$ & 0.984 & $<0.001$ \\
$\mathrm{~T}_{3}-\mathrm{T}_{2}$ & 0.920 & $<0.001$ \\
$\mathrm{~T}_{3}-\mathrm{T}_{1}$ & 0.968 & $<0.001$ \\
\hline
\end{tabular}

The accordance of distribution of the scores of 0 -other scores for $\Delta V_{i t a}^{*}$ and $<3.7-\geq 3.7$ scores for $\Delta E^{*}$ 
Table 4. Multiple comparisons between composite materials, discoloration solutions, and evaluation periods.

\begin{tabular}{|c|c|c|c|c|c|c|c|}
\hline$\Delta E^{*}$ & Solution & GIF & ESLF & FBF & FUF & FU & Total \\
\hline \multirow{6}{*}{$\Delta \mathrm{E}_{1}$} & Water & $0.42 \pm 0.27$ & $0.78 \pm 0.54$ & $1.24 \pm 0.30_{\mathrm{HI}}$ & $1.62 \pm 0.34_{\mathrm{GHI}}$ & $0.74 \pm 0.27$ & $0.96 \pm 0.54 a$ \\
\hline & Coke & $1.66 \pm 0.25 \mathrm{GHI}$ & $2.18 \pm 0.40_{\mathrm{GHI}}$ & $0.44 \pm 0.26$ & $1.92 \pm 1.78 \mathrm{GHI}$ & $1.70 \pm 0.38_{\mathrm{GHI}}$ & $1.58 \pm 0.99 a$ \\
\hline & Tea & $3.04 \pm 1.06_{\mathrm{EFGH}}$ & $3.36 \pm 0.75_{\mathrm{EFG}}$ & $3.32 \pm 1.36_{\mathrm{EFGH}}$ & $4.94 \pm 0.39 \mathrm{CDE}$ & $2.24 \pm 0.52 \mathrm{FGHI}$ & $3.38 \pm 1.21_{b}$ \\
\hline & Coffee & $4.58 \pm 0.41_{D E}$ & $3.58 \pm 0.89_{\mathrm{EFG}}$ & $3.56 \pm 1.58_{\mathrm{EFG}}$ & $6.9 \pm 0.84_{\mathrm{BC}}$ & $4.32 \pm 0.62 \mathrm{DEF}$ & $4.59 \pm 1.52 c$ \\
\hline & Wine & $7.30 \pm 0.91_{\mathrm{B}}$ & $6.16 \pm 1.48_{\mathrm{BCD}}$ & $7.36 \pm 1.29_{в}$ & $11.32 \pm 1.38_{A}$ & $7.84 \pm 0.3_{в}$ & $8.00 \pm 2.08 d$ \\
\hline & Total & $3.40 \pm 2.52 \mathrm{a}$ & $3.21 \pm 1.99 a$ & $3.18 \pm 2.65 \mathrm{a}$ & $5.34 \pm 3.78 b$ & $3.37 \pm 2.61_{\mathrm{a}}$ & \\
\hline \multirow{6}{*}{$\Delta \mathrm{E}_{2}$} & Water & $0.50 \pm 0.32 \mathrm{H}$ & $0.74 \pm 0.21_{\mathrm{GH}}$ & $0.84 \pm 0.35 \mathrm{GH}$ & $0.7 \pm 0.43 \mathrm{GH}$ & $1.02 \pm 0.43_{\mathrm{FGH}}$ & $0.76 \pm 0.37 \mathrm{a}$ \\
\hline & Coke & $0.96 \pm 0.42 \mathrm{FGH}$ & $1.38 \pm 1.21_{\mathrm{EFGH}}$ & $0.94 \pm 0.5 \mathrm{FGH}$ & $2.46 \pm 0.57 \mathrm{DEFGH}$ & $0.58 \pm 0.26_{H}$ & $1.26 \pm 0.91_{a}$ \\
\hline & Tea & $2.84 \pm 1.32_{\text {BCDEFG }}$ & $2.72 \pm 1.422_{\mathrm{CDEFGH}}$ & $3.1 \pm 1.68_{\text {BCDEF }}$ & $4.9 \pm 1.03_{\mathrm{ABC}}$ & $1.32 \pm 0.68_{\mathrm{EFGH}}$ & $2.98 \pm 1.65 b$ \\
\hline & Coffee & $4.00 \pm 0.24 \mathrm{BCD}$ & $3.40 \pm 1.02 \mathrm{BCDE}$ & $3.7 \pm 1.17_{\mathrm{BCD}}$ & $6.54 \pm 0.58 \mathrm{~A}$ & $4.24 \pm 0.74_{\mathrm{BCD}}$ & $4.38 \pm 1.36 c$ \\
\hline & Wine & $4.38 \pm 0.81_{\mathrm{ABCD}}$ & $3.32 \pm 1.75_{\mathrm{BCDE}}$ & $4.44 \pm 1.22_{A B C D}$ & $5.06 \pm 0.988_{A B}$ & $4.58 \pm 1.32_{\mathrm{ABCD}}$ & $4.36 \pm 1.29 c$ \\
\hline & Total & $2.54 \pm 1.74 a$ & $2.31 \pm 1.57$ a & $2.6 \pm 1.8 \mathrm{a}$ & $3.93 \pm 2.23 b$ & $2.35 \pm 1.88 \mathrm{a}$ & \\
\hline \multirow{6}{*}{$\Delta \mathrm{E}_{3}$} & Water & $0.72 \pm 0.15_{\mathrm{EF}}$ & $0.96 \pm 0.9_{\mathrm{DEF}}$ & $1.08 \pm 0.98_{\mathrm{DEF}}$ & $1.0 \pm 0.72 \mathrm{deF}$ & $1.2 \pm 0.98 \mathrm{CDEF}$ & $0.99 \pm 0.76 a b$ \\
\hline & Coke & $0.7 \pm 0.39_{\mathrm{EF}}$ & $1.64 \pm 0.96_{\mathrm{BCDEF}}$ & $0.98 \pm 0.54 \mathrm{deF}$ & $1.42 \pm 1.04_{\mathrm{BCDEF}}$ & $1.6 \pm 0.5 \mathrm{BCDEF}$ & $1.27 \pm 0.77$ \\
\hline & Tea & $0.32 \pm 0.19_{\mathrm{F}}$ & $0.92 \pm 1.29_{\mathrm{DEF}}$ & $0.3 \pm 0.29_{F}$ & $0.58 \pm 0.26 \mathrm{~F}$ & $1.48 \pm 0.97_{\text {BCDEF }}$ & $0.72 \pm 0.82 a b$ \\
\hline & Coffee & $0.58 \pm 0.28 F$ & $0.34 \pm 0.19 \mathrm{~F}$ & $0.58 \pm 0.33_{F}$ & $0.56 \pm 0.22 \mathrm{~F}$ & $0.48 \pm 0.36 \mathrm{~F}$ & $0.51 \pm 0.27 b$ \\
\hline & Wine & $2.96 \pm 1.63_{\mathrm{BCD}}$ & $2.84 \pm 1.69_{\mathrm{BCDE}}$ & $3.52 \pm 1.16_{\mathrm{B}}$ & $6.26 \pm 1.7_{A}$ & $3.26 \pm 1.38_{\mathrm{BC}}$ & $3.77 \pm 1.90 c$ \\
\hline & Total & $1.06 \pm 1.21_{a}$ & $1.34 \pm 1.35_{\mathrm{ab}}$ & $1.29 \pm 1.36_{a b}$ & $1.96 \pm 2.38 b$ & $1.6 \pm 1.25 \mathrm{ab}$ & \\
\hline
\end{tabular}

$a-c$ : No differences between the composites/solutions with the same letter for each evaluation period.

\section{DISCUSSION}

According to the results, viscosity was considered an effective factor for discoloration of RBCs and discoloration of the materials was affected by the type of colorant solution. Therefore, both $\mathrm{h}_{1}$ hypotheses were accepted.

The immersion period was set for 144 hours at $37{ }^{\circ} \mathrm{C}$ with regards to the previously reported methodology. 144 hours of immersion in vitro corresponded to about 6 months of immersion in colorant drinks in vivo $(16,17)$. A clinical contact type spectrophotometer and a colorimeter were used for the assessments, which were the most commonly accepted color change monitoring devices in the literature $(19,21,23,24)$. In addition, no color change $\left(\Delta \mathrm{E}^{*}=0\right)$ should be detected after immersion to colorant agent to obtain complete color stability for a material, which is almost impossible (25). Thus, acceptability and perceptibility terms are important to scale the level of color change. However, there is still no consensus for the cut points of perceptibility and acceptability of color change. O'Brien et al. (18) reported that, values of $\leq 2$ were clinically acceptable. Ragain and Johnston (26) considered $\leq 2.7$, and Douglas et al. (19) considered $\leq 1.7$ acceptable. Tuncer et al. (20) and Vichi et al. (10) mentioned $\geq 3.3$, whereas Celik et al. (23) and Kim and Lee (21) reported $\geq$ 3.7 as perceptible. Respective, values of $\geq 3.7 / \leq 6.8$ and $\geq$ $2.6 / \leq 5.5$ by Johnston and Kao (27) and Douglas et al. (19) were considered perceptible and acceptable cut points. In the present study, recent and the most frequently preferred values of 3.7 and 5.5 were considered cut points for perceptibility and acceptibility of color change, respectively.

A major disadvantage of RBC materials is the color change in long-term, clinically (17). The level of discoloration may vary among the quality of isolation, quality of polymerization, the effectiveness of polishing material, type of composite material, and also the type of staining solution/diet. This study has investigated two of these influencing factors, the type of RBC, and the colorant solution.

\subsection{Assessment according to the type of composite}

Composition, filler size, weight, volume, thickness, polymerization quality, and polishing quality parameters were reported to be effective factors on microhardness and color stability of resin composites, previously (28). In this in vitro study, all samples were prepared in uniform $2 \mathrm{~mm}$ in thickness and polymerized using the same LED curing unit for $20 \mathrm{~s}$, to maintain the standardization.

The level of discoloration for composites varies among the brand and content of the material (30). Clinical application of early generation flowable composites were restricted previously, because of their low mechanical properties (30). Water plays a role as a transporter for pigments to the resin matrix and accordingly, Dietschi et al. showed that level of discoloration is directly related to the water sorption rate (31). In addition, filler particles do not absorb water, therefore, the water sorption rate is also filler content dependent. RBCs 
with a lower amount of inorganic fillers (i.e., early generation flowable composites) presented weaker bond strength between the resin matrix and filler particles, resulting in greater water uptake, which may allow stain penetration and discoloration of the material (32). In addition, water sorption and hygroscopic expansion were considered positively correlated (33). Thus, some researchers reported that flowable composites can relieve internal polymerization shrinkage stress and provide similar marginal adaptation and clinical stability with regular viscosity composites $(33,34)$.

Composites used in this study were nanofilled (FU, FBF, and FUF)andnanohybrid(GIFandESLF)RBCsindifferentviscosities. The introduction of nanotechnology to flowable composites provided the combination of strength, polishability, gloss retention, wear resistance, and translucency or opacity of a conventional composite with elasticity, adaptation, and better handling of flowable composites $(30,32,35)$. Smoother restoration surfaces were provided using composites with a lower particle size as a result of better distribution within the resin matrix, previously (17). Accordingly, polymerization shrinkage was also minimized by almost $20 \%$ (35). In addition, a systematic review and meta-analysis study suggested new generation, nanofiller-included flowable composites with enhanced mechanical and physical properties, to be suitable for minimally invasive posterior restorations $(20,36)$. Another systematic review and meta-analysis study also reported good marginal adaptation, thereby lower marginal discoloration for low viscosity flowable composites for 3-year clinical follow-ups (33). According to our results, a regular viscosity composite, FUF presented significantly the highest level of color change $(5,34 \pm 3,78$ b) among others, regardless of the solution type $\left(\Delta \mathrm{E}_{1}\right.$ period, Table 4). This result might be related to the lower amount of inorganic fillers (65\% wt. and $46 \%$ vol.) of FUF composite than FU, GIF, and ESLS composites. Although FBF composite has the lowest amount of fillers (64.5\% wt. and $42 \%$ vol.), the amount of color change for FUF was greater than FBF. A stain-resistant co-monomer urethane dimethacrylate (UDMA) was determined to have a lower rate of water absorption, thereby enhancing the color stability of the resinbased material (16). Thus, UDMA in FU, GIF, ESLS, and also FBF composites might be responsible for this result, as it is only absent in FUF composite (Table 1). All composites except FUF, presented similar and imperceptible discolorations in our study, although there are slight differences in filler amounts (Table 1). Therefore, two high viscosity flowable composites (GIF and ESLS), a bulk fill composite (FBF), and a packable composite (FU) presented statistically similar amount of color changes. This result is consistent with the previous results of Szesz et al. (33) and Rosales-Leal et al. (34), in which viscosity was not found effective for the retention and discoloration rates. According to Sideridou et al. (37), triethylene glycol dimethacrylate (TEGDMA) has the highest water sorption capability, followed by diglycidyl ether dimethacrylate (BisGMA) and by UDMA. All composite materials include TEGDMA in this study, therefore this co-monomer might not be an effective factor in color change. However, all composite materials include
Bis-GMA except GIF composite. But also this exception did not provide a significant difference in color change.

\subsection{Assessment according to the type of colorant solution}

In the present study the control group, physiological solution did not cause significant color changes with $\Delta \mathrm{E}<$ 1.0 even after $144 \mathrm{~h}$ of immersion. With regard to previous studies, the level of discoloration for RBCs varies among the colorant agents. Bagheri et al. (38) and Barutcugil and Yildiz (16) mentioned coffee as one of the most effective colorant solutions for RBCs. Zajkani et al. (39) reported a greater color change in coffee and tea compared to coke and orange juice. Our results showed that the level of color change for coffee solution $(4,59 \pm 1,52 c)$ was below red wine, but above other solutions (Table 3$)$. It was considered perceptible $(\geq 3.7)$, but also acceptable $(\geq 5.5)$. Absorption and penetration of yellow colorants into the organic phase may be the explanation of the discoloration mechanism by coffee (17). Llena et al. (40) used red wine, coffee, cola, and distilled water as colorant solutions for discoloration of two different nanohybrids, two different ormocers, and one compomer for four weeks. Discoloration in all beverages was considered above clinically acceptable limits. Discoloration by red wine was considered greater than coffee, and followed by cola. Ardu et al. (29) reported greater color change was caused by red wine and followed by coffee, tea, orange juice, and cola. Also, Barutcugil and Yildiz (16) considered red wine the most effective colorant, followed by coffee. Inconsistent with the results of Llena et al. (40), Ardu et al. (29), and Barutcugil and Yildiz (16), red wine solution presented significantly the greatest level of color change $(8,00$ $\pm 2,08$ d) among other solutions in our study, regardless of the composite type (Table 3 ). Also, the combination of red wine with any composite presented unacceptable color change ( $\geq$ 5.5) and FUF composite was significantly the most affected one $\left(11,32 \pm 1,38_{A}\right)$. Tannins in red wine might be the reason for the greater discoloration rate, as having a strong discoloration capacity (17). Also, in accordance with the results of Ardu et al. (29) and Zajkani et al. (39) tea group presented a significantly greater level of color change $(3,38 \pm 1,21$ b) compared to water and coke groups, but lower level of color change than red wine and coffee groups. It was considered imperceptible $(\leq 3.7)$.

Opposing to our results, Ceci et al. (17) mentioned greater discoloration for coffee than red wine, previously. Whereas, they immersed the samples in cola solution before immersion in red wine and coffee, which might influence the final result. In addition, phosphoric acid including drink, coke, was not considered a strong colorant agent for composites $(17,40)$. However, there are several researches mentioning acidic drinks effective for the alterations in surface smoothness of the RBCs and consequently for extrinsic discoloration (17). Although exposure to acidic or alcoholic drinks was determined to be effective in color change clinically, that can only be simulated with thermocycle procedure in vitro (41). However in the present study, thermocycle procedure was not undergone, therefore, it is impossible to observe the effect of acidity for coke $(\mathrm{pH}: 2.52)$, red wine $(\mathrm{pH}: 3.50)$, and also coffee $(\mathrm{pH}: 4.50)$ (Table 2). 
In this study, the effectiveness of repolishing after discoloration was also assessed. Polishing materials used were flexible aluminum oxide $\left(\mathrm{Al}_{2} \mathrm{O}_{3}\right)$ discs, which were previously reported as gold standard polishing system for RBC materials (41). Red wine, coffee, and tea stains are both external and internal discolorations and because of the penetration of staining materials into the organic phase, only partial reverse in color was reported previously by repolishing (42). With regards to our results, a partial recovery was detected in color, which is inconsistent with the results of Villalta et al. (42) All composites and colorant combinations presented color changes in different levels, after repolishing. In addition, a greater level of color change was detected for the samples which had discolored more (Table $4, \Delta \mathrm{E}_{2}$ scores). The color of all samples did not exactly reverse back to the baseline colors, but the differences ( $\Delta \mathrm{E}_{3}$ scores) were all not perceptible $(<$ 3.7), except the samples of FU and red wine combination group $\left(6,26 \pm 1,7_{\mathrm{A}}\right.$; Table 4). Therefore, it might be interpreted that, the discoloration of the majority of the samples was reversed back, therefore repolishing procedure might be considered as an effective procedure for reversing the discoloration of RBCs back.

A crosscheck between spectrophotometry and colorimetry measurements was performed. In terms of perceptible color changes, a positive and very good correlation was found between $\Delta \mathrm{E}^{*}$ values and $\Delta V$ ita* values in this study, for all the evaluation periods (Table 5).

This study has also some limitations. As previously reported, the type of adhesive system may also play a role in restoration discoloration (17). This in vitro study is lacking some clinical information regarding this. The color stability of RBCs depends on the filler type, size, and concentration, as well as the type and concentration of initiators, inhibitors and activators, minor pigments, and unreacted carbon bonds (24). The color stability of the materials tested in this study might have also been influenced by these factors. In addition, different results might have been found with different brands and different shades of RBCs as well as different brands of polishing materials $(16,43)$.

\section{CONCLUSIONS}

Within the limitations of this study, viscosity was considered an effective factor for discoloration of RBCs, and color stability of new generation high viscosity flowable composites were found to be good and similar to the packable composite. Composite samples in red wine presented the greatest level of discoloration and followed by coffee, tea, coke, and physiological solution. Repolishing procedure was considered effective for reversing the surface discoloration of RBCs back.

\section{Conflict of Interest}

The manuscript has been read and approved by all the authors. No potential conflict of interest was reported by any of the authors in this study.

\section{Clinical relevance statement}

Surface discoloration of resin composite restorations may cause esthetic problems clinically. Bewaring of colorant solutions may inhibit the level of discoloration. Also, the repolishing procedure may have a discoloration reversing effect for the discolored restoration surfaces. The present study assessed the effectiveness of different colorant solutions and repolishing on the color stability of composite samples, while the color stability of new generation high viscosity flowable composites were also evaluated.

\section{REFERENCES}

[1] Korkut B, Yanıkoğlu F, Günday M. Direct composite laminate veneers: three case reports. J Dent Res Dent Clin Dent Prospects 2013; 7(2):105-111.

[2] Guler AU, Duran I, Yucel AÇ, Ozkan P. Effects of air-polishing powders on color stability of composite resins. J Appl Oral Sci 2011; 19: 505-510.

[3] Gaengler P, Hoyer I, Montag R, Gaebler P. Micromorphological evaluation of posterior composite restorations - A 10 year report. J Oral Rehabil 2004; 31: 991-1000.

[4] Lazzetti G, Burgess JO, Gardiner D, Ripps A. Color stability of fluoride-containing restorative materials. Oper Dent 2000; 25: 520-525.

[5] Sarac D, Sarac YS, Kulunk S, Ural C, Kulunk T. The effect of polishing techniques on the surface roughness and color change of composite resins. J Prosthet Dent 2006; 96: 33-40.

[6] Rajkumar K, Kumar S, Mahalaxmi S, Ragavi P, Mageshwaran TA. Colour stability of resin composites after emersing in coffee of different temperature - an in vitro study. SRM J Dent

Sci 2011; 2: 91-95.

[7] Janus J, Fauxpoint G, Arntz Y, Pelletier H, Etienne O. Surface roughness and morphology of three nanocomposites after two different polishing treatments by a multitechnique approach. Dent Mater 2010; 26: 416-425.

[8] Kocaağaoğlu H, Aslan T, Gürbulak A, Albayrak H, Taşdemir Z, Gumus $\mathrm{H}$. Efficacy of polishing kits on the surface roughness and color stability of different composite resins. Niger J Clin Pract 2017; 20(5): 557-565.

[9] Moraes RR., Goncalves LDS, Lancellotti AC, Consani S, Sobrinho LC, Sinhoreti MA. Nanohybrid resin composites: nanofiller loaded materials or traditional microhybrid resins?. Oper Dent 2009; 34(5): 551-557.

[10] Vichi A, Ferrari M, Davidson CL. Color and opacity variations in three different resin-based composite products after water aging. Dent Mater., 2004; 20: 530-534.

[11] Mitra SB, Wu D, Holmes BN. An application of nanotechnology in advanced dental materials. J Am Dent Assoc 2003; 134: 1382-1390.

[12] Plotino G, Buono L, Grande NM, Pameijer CH, Somma F. Nonvital tooth bleaching: a review of the literature and clinical procedures. J Endod 2008; 34: 394-407.

[13] Berger SB, Palialol ARM, Cavalli V, Giannini M. Surface roughness and staining susceptibility of composite resins after finishing and polishing. J Esthet Restor Dent 2011; 23(1): 34-43. 
[14] Jefferies SR. The art and science of abrasive finishing and polishing in restorative dentistry. Dent Clin North Am 1998; 42: 613-627.

[15] Olmez A, Kisbet S. Kompozit rezin restorasyonlarda bitirme ve polisaj islemlerindeki yeni gelismeler. Acta Odontol Turc 2013; 30(2): 115-122.(Turkish)

[16] Barutcugil C , Yildiz M. Intrinsic and extrinsic discoloration of dimethacrylate and silorane based composites. J Dent 2012; 40: 57-63.

[17] Ceci M, Viola M, Rattalino D, Beltrami R, Colombo M, Poggio C. Discoloration of different esthetic restorative materials: A spectrophotometric evaluation. Eur J Dent 2017; 11(2): 149156.

[18] O'Brien WJ, Groh CL, Boenke KM. A new, small color difference equation for dental shades. J Dent Res 1990; 9(11): 1762-1764.

[19] Douglas RD, Steinhauer TJ, Wee AG. Intraoral determination of the tolerance of dentists for perceptibility and acceptibility of shade mismatch. J Prosthet Dent 2007; 97(4): 200-208.

[20] Tuncer S, Demirci M, Tiryaki M, Ünlü N, Uysal Ö. The effect of a modeling resin and thermocycling on the surface hardness, roughness, and color of different resin composites. J Esthet Restor Dent 2013; 25(6): 404-419.

[21] Kim BJ, Lee YK. Influence of the shade designation on the color difference between the same shade-designated resin composites by the brand. Dent Mater 2009; 25(9): 1148-1154.

[22] Zimmerli B, Koch T, Flury S, Lussi A. The Influence of Toothbrushing and Coffee Staining on Different Composite Surface Coatings. Clin Oral Investig 2012; 16(2): 469-479.

[23] Celik EU, Aladağ A, Türkün LŞ, Yilmaz G. Color changes of dental resin composites before and after polymerization and storage in water. J Esthet Restor Dent 2011; 23(3): 179-188.

[24] Pedroso LB, Barreto LF, Miotti LL, Nicolosoo GF, Durand LB. Effect of a surface sealant on the color stability of composite resins after immersion in staining solution. Gen Dent 2016; 64(2): 22-25.

[25] Tekçe N, Pala K, Tuncer S, Demirci M. The effect of surface sealant application and accelerated aging on posterior restorative surfaces: An SEM and AFM study. Dent Mater 2017; 36(2): 182-189.

[26] Ragain JC, Jonston WM. Color acceptance of direct dental restorative materials by human observers. Color Res Appl 2000; 25(4): 278-285.

[27] Johnston WM, Kao EC. Assessment of appearance match by visual observation and clinical colorimetry. J Dent Res. 1989; 68(5): 819-822.

[28] AlShaafi MM. Factors affecting polymerization of resin - based composites: A literature review. Saudi Dent J 2017; 29: 48-58.

[29] Ardu S, Braut V, Gutemberg D, Krejci I, Dietschi D, Feilzer AJ. A long-term laboratory test on staining susceptibility of esthetic composite resin materials. Quintessence Int 2010; 41(8): 695-702.
[30] Baroudi K, Rodrigues JC. Flowable resin composites: A Systematic review and clinical considerations. J Clin Diagn Res 2015; 9: 18-24.

[31] Dietschi D, Campanile G, Holz J, Meyer JM. Comparison of the color stability of ten new-generation composites: An in vitro study. Dent Mater 1994; 10: 353-362.

[32] Fontes ST, Fernández MR, de Moura CM, Meireles SS. Color stability of a nanofill composite: Effect of different immersion media. J Appl Oral Sci 2009; 17: 388-391.

[33] Szesz A, Parreiras S, Martini E, Reis A, Loguercio A. Effect of flowable composites on the clinical performance of noncarious cervical lesions: A systematic review and metaanalysis. J Dent 2017; 65: 11-21.

[34] Jl Rosales-Leal, RD Castillo-Salmeron, MA Molino-Serrano, H Gonzalez-Moreira, MA Cabrerizo-Vilchez. Effect of hygroscopic expansion of resin filling on interfacial gap and sealing: a confocal microscopy study, J Adhes Dent 2013; 15: 423-430.

[35] Abiodun-Solanke I, Ajayi D, Arigbede A. Nanotechnology and its application in dentistry. Ann Med Health Sci Res 2014; 4: 171-177.

[36] Shaalan OO, Abou-Auf E, El Zoghby AF. Clinical evaluation of flowable resin composite versus conventional resin composite in carious and noncarious lesions: Systematic review and metaanalysis. J Conserv Dent 2017; 20(6): 380-385.

[37] Sideridou I, Tserki V, Papanastasiou G. Study of water sorption, solubility and modulus of elasticity of light-cured dimethacrylate-based dental resins. Biomater 2003; 24:655665.

[38] Bagheri R, Burrow MF, Tyas M. Influence of food-simulating solutions and surface finish on susceptibility to staining of aesthetic restorative materials. J Dent 2005; 33(5): 389-398.

[39] Zajkani E, Abdoh Tabrizi M, Ghasemi A, Torabzade, H, Kharazifard $\mathrm{M}$. Effect of staining solutions and repolishing on composite resin color change. J Islam Dent Assoc 2013; 25(3): 139-146.

[40] Llena C, Fernández S, Forner L. Color stability of nanohybrid resin-based composites, ormocers and compomers. Clin Oral Invest 2017; 21(4): 1071-1077.

[41] Poggio C, Dagna A, Chiesa M, Colombo M, Scribante A. Surface roughness of flowable resin composites eroded by acidic and alcoholic drinks. J Conserv Dent 2012; 15: 137-140.

[42] Villalta P, Lu H, Okte Z, Garcia-Godoy F. Effects of staining and bleaching on color change of dental composite resins. J Prosthet Dent 2006; 95(2): 137-142.

[43] Manabe A, Kato $Y$, Finger WJ, Kanehira $M$, Komatsu $M$, Werner J. Discoloration of coating resin exposed to staining solutions in vitro. Dent Mater 2009; 28(3): 338-343. 